Bulletin of Electrical Engineering and Informatics

Vol. 11, No. 1, February 2022, pp. 111 118

ISSN: 2302-9285, DOI: 10.11591/eei.v11i1.3304

\title{
Design and modeling industrial intelligent robot flexible hand
}

\author{
Mikhail Polishchuk ${ }^{1}$, Mikhail Tkach ${ }^{1}$, Igor Parkhomey ${ }^{1}$, Juliy Boiko², Oleksander Eromenko ${ }^{3}$ \\ ${ }^{1}$ Department of Information Systems and Technologies, National Technical University of Ukraine "Igor Sikorsky Kyiv Polytechnic \\ Institute, Kyiv, Ukraine \\ ${ }^{2}$ Department of Telecommunications, Media and Intelligent Technologies, Khmelnytskyi National University, Khmelnytskyi, Ukraine \\ ${ }^{3}$ Department of Physics and Electrical Engineering, Khmelnytskyi National University, Khmelnytskyi, Ukraine
}

\begin{tabular}{l} 
Article Info \\
\hline Article history: \\
Received Oct 28, 2021 \\
Revised Dec 11, 2021 \\
Accepted Jan 7, 2022
\end{tabular}

Keywords:

Anthropomorphic devices

Gripping devices

Industrial robots

Manipulators

\begin{abstract}
The article describes a description of a fundamentally new design, mathematical model and experimental research of a flexible arm with an anthropomorphic gripper for an industrial robot. The advantage of the proposed design of the robot arm in comparison with the known traditional technical solutions is achieved as close as possible to the functions of the human arm. This property significantly increases the versatility of the robot arm when performing various technological operations. Another difference from the known models of industrial robots is the presence of an anthropomorphic gripping device in the flexible arm, which allows you to service products with different shapes and arbitrary coordinates in space. In addition, the article for the first time proposes a method for calculating the parameters of a new hand and experimental studies of its functioning, which will allow engineers in the field of robotics to create similar designs. The economic effect of the proposed design is that the implementation of the movements of the proposed robot arm does not require separate electromechanical drives for each joint of the kinematic chain of the manipulator. This effect significantly reduces the cost of a robot arm while expanding its technological capabilities.
\end{abstract}

This is an open access article under the CC BY-SA license.

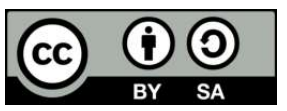

\section{Corresponding Author:}

Juliy Boiko

Department of Telecommunications, Media and Intelligent Technologies

Khmelnytskyi National University, 11, Instytuts'ka str., Khmelnytskyi, 29016, Ukraine

Email: boiko_julius@ukr.net

\section{INTRODUCTION}

Modern manipulators of industrial robots, as a rule, are made in the form of an open kinematic chain, in which each link has a separate electromechanical drive. The number of these drives determines the number of degrees of freedom of the industrial robot. Such technical solutions of robotic arm are widespread in industries for various purposes. However, the presence of a separate electric or hydraulic drive for each kinematic link increases the weight of the robot arm and its dynamic loads.

In addition, equipping each joint of the hand and fingers of the gripper with separate motor increases energy consumption. The robot arm manipulates the object of production, and its gripper is designed to hold various blanks, semi-finished products and finished products. This article proposes technical solutions for a robot arm and its gripper in the form of anthropomorphic structures, which expand the technological capabilities of an industrial robot, increase its versatility due to the approximation to the functioning of a human hand and fingers of the gripper.

One of the promising directions in the development of robotics is the creation of anthropomorphous structures that are as close as possible to the skeleton and human image. This direction is explained by the desire to increase the versatility of industrial robots of classical design [1], [2]. Known robot manipulators are 
capable of performing a wide variety of industrial operations. However, there are many objects with an indefinite shape, for example, agricultural products: vegetables and fruits. In these cases, the classical designs of manipulators do not satisfy the production conditions.

At present, original designs of gripping devices for robots are known, which are quite close to the device of a human hand. However, these devices operate on a rigid cycle and are not flexible enough for a variety of technological operations. For example, a soft robot arm [3]-[5] with tactile feedback for remote control is known. This hand is designed to perform complex tasks and ensure safe human-machine interaction. However, this hand works only with the direct participation of a person, more precisely the operator's hand, on which a glove with tactile sensors is put on to process information about the angles of the operator's hand joints.

A manipulator with several degrees of freedom is illustrated. This manipulator resembles a human hand in its construction and contains flexible kinematic links, with each finger having three movable links [6]. The manipulator of this robot can grip objects of various shapes, for example, rectangular, cylindrical or spherical. But all drives of the fingers of the gripper are made in the form of cables and act simultaneously, that is, they do not allow the fingers to work autonomously. Consequently, each phalanx of the fingers does not have the ability to work offline. This design has limited options for freeform products. A robot for climbing trees is proposed. The flexibility of the body of this robot is provided by the deformation of elastic rods with drives [7]. The robot is best suited for video observation of trees, but has a low load capacity.

In work [8]-[10], studies of the gripping of a robot with electrical adhesion are presented. This device allows you to grip almost all objects, regardless of their shape or type of material, using Maxwell's electrostatic force. In this work, the lift force of the electrical adhesion device exceeds the grip force of a human finger. The original design of the 5-finger grip [11], [12] has an anthropomorphic design, in which the fingers consist of separate phalanges, but each finger has a single drive for its phalanges. Therefore, the phalanges cannot work offline. A mechanical adjustable device, which consists of flexible rods, can be used to construct an anthropomorphic arm for working in 3D space. However, this device does not have a gripping element for holding production objects. In works [13]-[17], original designs of anthropomorphic grips for manipulators are proposed, but these fingers of these grips work only in 2D space. Due to the indicated drawback, this device cannot work in the angular coordinate system of three-dimensional space. The problem of adapting the functions of an industrial robot [18]-[20] is not limited to the creation of anthropomorphic structures. The solution of this problem also requires the creation of an appropriate optimal control, the studies of which are presented in [21], [22]. Prospective studies are projects to create robotic exoskeletons for the rehabilitation of the upper limb of a person [23]. These works are examples of adaptation of the movement of a robot arm and a human hand. Pedipulators of a mobile robot [24] are made in the form of anthropomorphic structures, but this robot does not contain devices for gripping and holding production objects. The surgical robot [25] has increased positioning accuracy due to a special program, but four degrees of freedom are not enough to simulate the movement of a human hand. The mobile robot [26] has three-tube soft drives, and uses vacuum suction cups as a gripper. The flexible body of this robot is as close as possible to the likeness of soft-bodied organisms. However, the vacuum grippers of this robot do not possess the invariance that is characteristic [27] of the human hand. The above designs of anthropomorphic grippers indicate the prospects for their development, which confirms the relevance of this problem.

It is necessary to create anthropomorphic constructions of a hand and its hand for an industrial robot, that is, structures that can function in an arbitrary coordinate system. The robot hand must be capable of performing various manipulations with objects in an arbitrary coordinate system, at least close to the human hand. Traditional manipulators of industrial robots have an autonomous motor for each degree of freedom, which increases the weight of the manipulator and its dynamic loads. Therefore, it is also necessary to minimize the number of motors for the hand and arm of the robot. The solution to this problem will allow not only to reduce the dynamic loads on the robot arm, but it is also necessary to reduce the energy costs of the industrial manipulator. Another important task is the synthesis of models for designing a flexible robot arm.

\section{RESEARCH METHOD}

In this section, it is explained the results of research method and at the same time obtained scientific novelty. The engineering novelty of the proposed technical solutions consists in fundamentally new designs of the robot arm and hand, and the scientific novelty is determined by analytical dependencies for calculating the design parameters of a flexible robot arm. The main motivation for these studies is to increase the level of versatility of the robot arm with the maximum possible approximation to the functions of the human arm and at the same time to reduce the number of motors to reduce dynamic loads during various technological operations.

Bulletin of Electr Eng \& Inf, Vol. 11, No. 1, February 2022: 111-118 


\subsection{Design of flexible robot hand}

The first of the above tasks is a constructive task. The solution to this problem is carried out as shown in: A flexible arm, which is assembled from spherical rings Figure 1(a), is mounted on the base. An anthropomorphic gripper is installed on the hand by means of a hinged connection with an electric motor, which performs the functions of gripping production objects. The presence of an electric motor is not necessary, this motor performs an auxiliary function when the bending of the arm is not enough. The anthropomorphic gripper of the flexible arm of the robot is made in the form of a flange on which five fingers are placed, namely: thumb, index, middle ring and small fingers. The number of phalanges of each of the five fingers is equal to the number of phalanges of the human hand. Each phalanx consists of four pneumatic bellows made of elastic material. The design of the phalanges of the fingers is discussed in more detail below. A dynamic model of a similar design, but in the form of pedipulators of a mobile robot, is considered in [28], [29]. Here we will consider the construction of a flexible arm Figure 1(b).

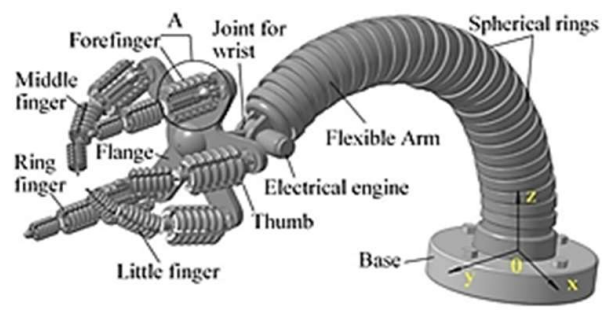

(a)

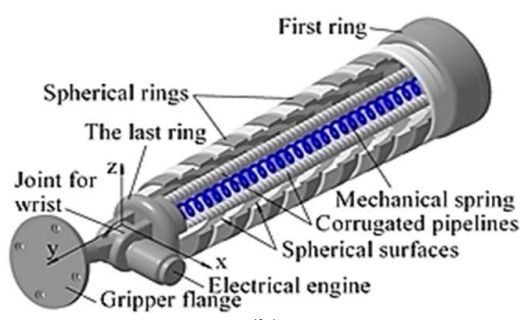

(b)

Figure 1. Construction of a flexible arm and its constituent parts (a) flexible arm of a robot with anthropomorphic gripper and (b) the design of the robot arm in a section of $1 / 4$ volume

\subsection{Design of robot hand anthropomorphic gripper}

As noted in Figure 1, detail "A", the gripper of the hand is made as close as possible to the human hand, namely: the gripper contains five fingers-four fingers have three phalanges, and the fifth thumb has two phalanges. All phalanges have absolutely identical design and differ only in geometric dimensions, which are proportionally reduced in the direction from the large phalanx to the lesser phalanx. For a better understanding of the design, Figure 2(a) shows the assembled phalanx of each toe, and Figure 2(b) shows the phalanx in an exploded view of all its parts.

The phalanges of all fingers contain four corrugated chambers. Each chamber has a small and large corrugated shell. When a gas or liquid pressure is created inside the chamber, the corrugated chambers are bent in the direction of the small corrugated shell. This is due to the fact that the surfaces of the upper and inner chambers have different areas. The left end surfaces in Figure 2(b) of these cameras are installed on the cross. This crosspiece has the ability to move along the shaft. The arm, which is rigidly fixed to the flange, has a ball joint (hinge), which is connected to the longitudinal shaft. This shaft has the ability to freely rotate in the $Z X Y$ coordinate system at angles $\pm \varphi_{z}, \pm \varphi_{x}, \pm \varphi_{y}$ and ends with the same ball joint for connecting to the next smaller phalanx of the finger in the coordinate system $z_{1}, x_{1}, y_{1}$. At various combinations of pressures $p_{1}$, $p_{2}, p_{3,} p_{4}$ in pneumatic corrugated chambers, these chambers are proportionally bent at different angles in the $Z X Y$ coordinate system.

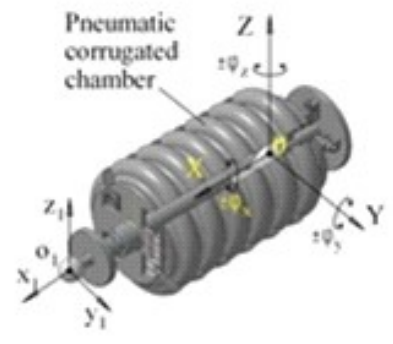

(a)

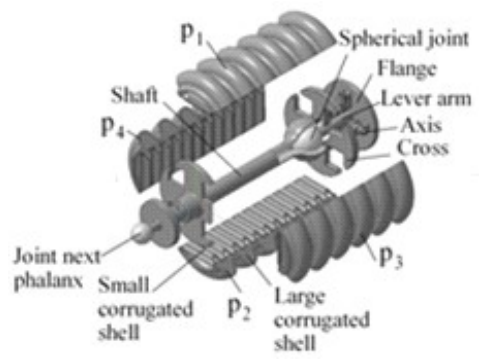

(b)

Figure 2. Robot arm phalanx modules (a) is the assembled view and (b) is the exploded view 
Thanks to the specified control algorithm, the fingers of the gripper are able to grip and hold objects of arbitrary shape. For example, Figure 3 shows options for grabbing fruits (a, b) and vegetables (c, d). The elasticity of the corrugated chambers, which are made of a material such as polyvinyl chloride, eliminates the possibility of damaging soft objects. The flexible arm of the robot has a similar control. The only difference is that different combinations of gas or liquid pressure are generated in flexible arm corrugated pipelines (see Figure 2 and Figure 3).

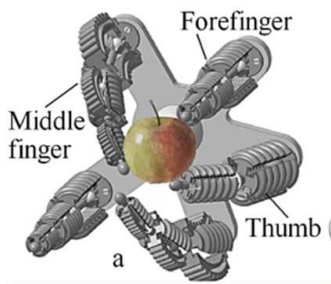

(a)

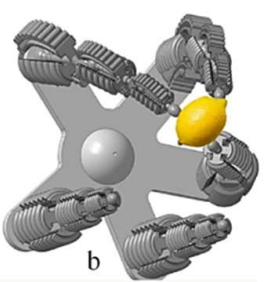

(b)

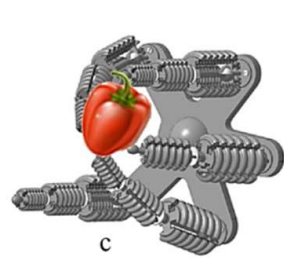

(c)

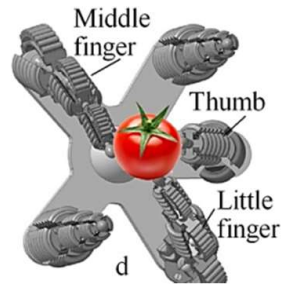

(d)

Figure 3. Finger gripping options for fruits and vegetables where option; (a) corresponds to grabbing an apple

(fruit) option, (b) corresponds to grabbing a lemon (fruit) option, (c) corresponds to an example of a hand gripping sweet pepper and option, (d) is an example of a hand grabbing tomatoes which are vegetables

\section{RESULTS AND DISCUSSION}

In this section, it is explained the results of the synthesis of analytical dependences for calculating the parameters of the flexible arm and its anthropomorphic gripper. At the same time, it was taken into account that the hand and its hand work in an autonomous mode, and the coordination of their actions in an arbitrary coordinate system is carried out by specialized programming.

\subsection{Simulation of a flexible hand}

The orientation of the flexible arm in space is determined by the program, which is based on the analytical dependences of forces and bending moments, as well as on the equations for the coordinates of the arm axis bending. Pressurizing compressed air or liquid (e.g., machine oil) creates forces inside the pipelines:

$$
F_{1}=p_{1} \frac{\pi d^{2}}{4} ; F_{2}=p_{2} \frac{\pi d^{2}}{4} ; F_{3}=p_{3} \frac{\pi d^{2}}{4} ; F_{4}=p_{4} \frac{\pi d^{2}}{4}
$$

where $d$ is the diameter of the end surface of pipelines; $p_{1}, p_{2}, \mathrm{p}_{3}, p_{4}$ - pressure in pipelines.

For arbitrary orientation of the hand, bending moments from the indicated forces are required (1). Such moments of forces arise due to the fact that the axes of the pipelines are displaced relative to the central axis of the hand by the amount of eccentricity «e»can be seen Figure 2:

$$
M_{1}=\frac{\pi d^{2}}{4}\left(p_{1}-p_{2}\right) e ; M_{2}=\frac{\pi d^{2}}{4}\left(p_{3}-p_{4}\right) e
$$

The total moment will be equal to:

$$
M=|\vec{M}|=\sqrt{\left(\vec{M}_{1}\right)^{2}+\left(\vec{M}_{2}\right)^{2}}=\frac{\pi d^{2}}{4} e \sqrt{\left(p_{1}-p_{2}\right)^{2}+\left(p_{3}-p_{4}\right)^{2}}
$$

The bending angle of the robot arm is determined by the formula:

$$
\left.\beta=\operatorname{arctg}\left(\frac{p_{1}-p_{2}}{p_{3}-p_{4}}\right) ; p_{3}>p_{4} ; \beta=\pi+\operatorname{arctg}\left(\frac{p_{1}-p_{2}}{p_{3}-p_{4}}\right) ; p_{3}<p_{4} .\right)
$$

The equations for the coordinates of the arm bending axis are:

$$
\left\{\begin{array}{l}
x=R \sin \varphi \\
y=(R \cos \varphi-R) \cos \beta 0 \leq \varphi \leq \frac{L}{R} \\
z=(R \cos \varphi-R) \sin \beta
\end{array}\right.
$$

The calculation of an elastic element in the form of a mechanical spring is known. However, in order to increase the carrying capacity of the flexible arm, it is advisable to use a flexible rod as a tightening element. The tensile force $Q$ of such an element will be: 


$$
Q \geq F=\left(p_{1}+p_{2}\right) \frac{\pi d^{2}}{4}
$$

As a result of modeling a flexible robot arm, the dependences of the pressure $\left(p_{1}-p_{2}\right)$ difference in corrugated pipelines and the bending angle $\beta$ of the robot arm were obtained as shown in Figure 4, as well as the dependence of the bending moment " $M$ " on the angle $\beta$ of the arm bend as shown in Figure 5.

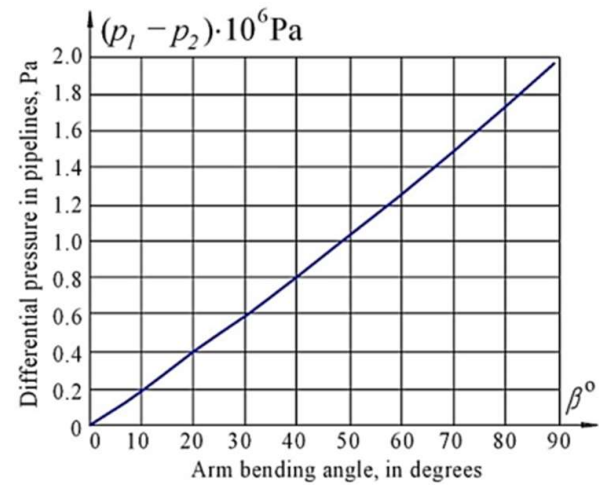

Figure 4. Dependence of the difference in pressures $\left(p_{1}-p_{2}\right)$ in corrugated pipelines and the angle $\beta$ of the bend of the hand condition

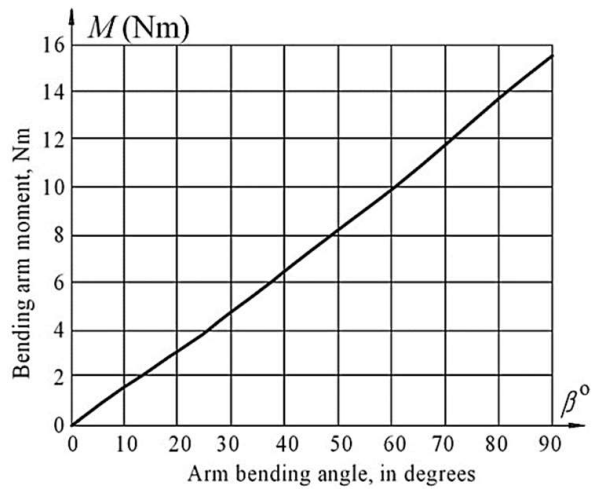

Figure 5. The relationship between the bending moment $M$ and the bending angle $\beta$ of the arm

Obviously, the dependences between the pressure difference $\left(p_{1}-p_{2}\right)$ and between the bending moment $M$ on the angle $\beta$ of the arm bending work are almost proportional. A small deviation from proportionality is created by the component $(\beta e / L)^{2}$, where: $e$ - eccentricity; $L$ - is the length of the pipeline.

\subsection{Experimental studies of the process of bending the arm of the robot}

The purpose of the experiment is to determine the influence on the torque $M_{1}$ of the arm flexion of such factors as the difference in pressure $\left(p_{1}-p_{2}\right)$, diameter " $d$ " and eccentricity " $e$ ". Let's hypothetically represent the objective function as:

$$
M_{1}=C_{0} f_{1}\left(p_{1}-p_{2}\right) f_{2}(d) f_{3}(e) \rightarrow \max
$$

Under the accepted restrictions, the change of variables in (7):

$$
5 \times 10^{5} \mathrm{~Pa} \leq\left(p_{1}-p_{2}\right) \leq 15 \times 10^{5} \mathrm{~Pa} ; 0,02 \mathrm{~m} \leq d \leq 0,04 \mathrm{~m} ; 0,025 \mathrm{~m} \leq e \leq 0,045 \mathrm{~m}
$$

The results of the experiment are shown in Table 1, indicating the average value of the bending moment of the robot arm.

Table 1. The results of the experiment

\begin{tabular}{cccccc}
\hline $\begin{array}{c}\text { no. } \\
\text { points }\end{array}$ & \multicolumn{2}{c}{$\begin{array}{c}\text { Torque } M_{1}(\mathrm{Nm}) \\
\text { n with the number of experiments }\end{array} \rightarrow M_{1} \ldots M_{3} ; y_{i}=\ln M_{i}$} & Average value $M_{1}(N m)$ & $\bar{y}_{i}=\ln \bar{M}_{i}$ \\
plan & $M_{1},\left(y_{i}\right)$ & $M_{2},\left(y_{i}\right)$ & $M_{3},\left(y_{i}\right)$ & $\bar{M}_{i}$ & $\bar{y}_{i}$ \\
\hline 1 & $85,(4.44)$ & $93,(4.53)$ & $91,(4.51)$ & 89 & 4.49 \\
2 & $28,(3.34)$ & $32,(3.46)$ & $30(3.40)$ & 30 & 3.40 \\
3 & $21,(3.04)$ & $24,(3.18)$ & $22,(3.09)$ & 22 & 3.09 \\
4 & $7.0,(1.95)$ & $8.4,(2.13)$ & $8.0,(2.08)$ & 7.8 & 2.05 \\
5 & $47,(3.85)$ & $42,(3.74)$ & $44,(3.78)$ & 44 & 3.78 \\
6 & $16,(2.77)$ & $18,(2.89)$ & $17,(2.83)$ & 17 & 2.83 \\
7 & $12,(2.48)$ & $17,(2.83)$ & $14,(2.64)$ & 14 & 2.64 \\
8 & $3.9,(0.07)$ & $5.1(1.63)$ & $4.0(1.38)$ & 4.3 & 1.46 \\
\hline
\end{tabular}

After statistical analysis according to the classical technique [30]-[34], a regression model of the dependence of the bending moment on factors in coded variables was obtained:

$$
y=2,97+0,53 x_{1}+0,66 x_{2}+0,29 x_{3}
$$


The function (9) obtained as a result of the experiment shows thatthe diameter parameter " $d$ " (coded designation $x_{2}$ ) is dominant for the increase in torque, and vice versa, the eccentricity parameter " $e$ " (coded designation $x_{3}$ ) has the least effect on the bending torque of the robot arm. Thus, in contrast to the abovementioned in the Introduction section of analog solutions to problems, the data indicate the direction of effective control of the torque of the arm of the robot in different planes of the coordinate system.

\subsection{Analysis of the obtained results and discussion}

Unlike the traditional designs of industrial robots' manipulators discussed above, when each link of the kinematic chain of the manipulator has a separate motor, the proposed flexible arm contains a single pressure generator in the corrugated elements of the robot arm. Moreover, the specified pressure generator is installed permanently and does not affect the weight of the hand. The described approach allows one to significantly reduce the weight of the robot arm and, accordingly, also to reduce the dynamic loads [35], [36]. The automatic solenoid valves and pressure regulators for compressed air or liquid used in the control unit are significantly lighter than electric or other types of motors.

The use of pressures of compressed air or pressurized fluid, such as machine oil, is determined by the technological purpose of the robot arm. If the requirements for the positioning accuracy of the hand are not stringent and a high speed of the hand is required, then the pneumatic actuator should be preferred. When it is necessary to provide increased positioning accuracy and increased lifting capacity of the hand, then a hydraulic drive should be used, because a hydraulic drive has such a well-known positive property as high power density. The principal design of the flexible hand is invariant to both pneumatic and hydraulic drive. However, the transition to hydraulic drive requires the use of stronger materials and hydraulic automation. However, in both cases, the proposed flexible arm of the robot has a free orientation in space.

\section{CONCLUSION}

A fundamentally new implementation of the flexible arm of the robot in the form of a set of spherical rings with corrugated pipelines inside, which are controlled by the difference in gas pressure (compressed air) or fluid pressure (machine oil), makes it possible to orient the hand in an arbitrary coordinate system, including an angular one coordinate system, which is characteristic of the human hand. The implementation of the hand gripper in the form of an anthropomorphic structure, namely when the phalanges of the fingers are made in the form of corrugated elastic chambers, makes it possible to grip production objects of arbitrary shape, as well as objects whose shape is not known apriori, for example, agricultural objects: fruits and vegetables. Taken together, these differences in the flexible arm design significantly expand the technological capabilities of industrial robots. The proposed methodology, in contrast to previous studies, is based on experimental testing of the regression model of the functioning of a robot arm, and the created functional dependencies make it possible to program the orientation of the arm movement in arbitrary coordinate systems. In addition, the proposed methodology makes it possible to calculate the design parameters of the hand depending on its power loads and technological purpose. Ultimately, the economic effect of the proposed design is that the implementation of the movements of the proposed robot arm does not require separate electromechanical drives for each joint of the kinematic chain of the manipulator. This effect significantly reduces the cost of a robot arm while expanding its technological capabilities.

\section{REFERENCES}

[1] P. Mesmer, M. Neubauer, A. Lechler, and A. Verl, "Robust design of independent joint control of industrial robots with secondary encoders," Robotics and Computer-Integrated Manufacturing, vol. 73, p. 102232, Feb. 2022, doi: 10.1016/j.rcim.2021.102232.

[2] W. S. Pambudi, E. Alfianto, A. Rachman, and D. P. Hapsari, "Simulation design of trajectory planning robot manipulator," Bulletin of Electrical Engineering and Informatics, vol. 8, no. 1, pp. 196-205, Mar. 2019, doi: 10.11591/eei.v8i1.1179.

[3] M. Li et al., "Design and performance characterization of a soft robot hand with fingertip haptic feedback for teleoperation," Advanced Robotics, vol. 34, no. 23, pp. 1491-1505, Dec. 2020, doi: 10.1080/01691864.2020.1822913.

[4] A. A. Sipos and P. L. Várkonyi, "The longest soft robotic arm," International Journal of Non-Linear Mechanics, vol. 119, p. 103354, Mar. 2020, doi: 10.1016/j.ijnonlinmec.2019.103354.

[5] F. Xu, H. Wang, J. Wang, K. W. S. Au, and W. Chen, "Underwater Dynamic Visual Servoing for a Soft Robot Arm With Online Distortion Correction," IEEE/ASME Transactions on Mechatronics, vol. 24, no. 3, pp. 979-989, Jun. 2019, doi: 10.1109/TMECH.2019.2908242.

[6] A. Sharma and M. M. Noel, "Design of a low-cost five-finger anthropomorphic robotic arm with nine degrees of freedom," Robotics and Computer-Integrated Manufacturing, vol. 28, no. 4, pp. 551-558, Aug. 2012, doi: 10.1016/j.rcim.2012.01.001.

[7] A. P. Dubey, S. M. Pattnaik, A. Banerjee, R. Sarkar, and S. K. R., "Autonomous Control and Implementation of Coconut Tree Climbing and Harvesting Robot," Procedia Computer Science, vol. 85, pp. 755-766, 2016, doi: 10.1016/j.procs.2016.05.263.

[8] K. Choi et al., "Lifting-Force Maximization of a Micropatterned Electroadhesive Device Comparable to the Human-Finger Grip,"

Bulletin of Electr Eng \& Inf, Vol. 11, No. 1, February 2022: 111-118 
ACS Applied Electronic Materials, vol. 2, no. 6, pp. 1596-1602, Jun. 2020, doi: 10.1021/acsaelm.0c00188.

[9] L. B. Amar and W. M. Jasim, "Hybrid metaheuristic approach for robot path planning in dynamic environment," Bulletin of Electrical Engineering and Informatics, vol. 10, no. 4, pp. 2152-2162, Aug. 2021, doi: 10.11591/eei.v10i4.2836.

[10] M. Polishchuk, M. Tkach, I. Parkhomey, J. Boiko, and O. Eromenko, "Experimental Studies on the Reactive Thrust of the Mobile Robot of Arbitrary Orientation," Indonesian Journal of Electrical Engineering and Informatics (IJEEI), vol. 8, no. 2, May 2020, doi: 10.52549/ijeei.v8i2.1681.

[11] J. Narayan, S. Mishra, G. Jaiswal, and S. K. Dwivedy, "Novel design and kinematic analysis of a 5-DOFs robotic arm with threefingered gripper for physical therapy," Materials Today: Proceedings, vol. 28, pp. 2121-2132, 2020, doi: 10.1016/j.matpr.2020.04.017.

[12] T. L. Nguyen and H. T. Vu, "Super-twisting sliding mode based nonlinear control for planar dual arm robots," Bulletin of Electrical Engineering and Informatics, vol. 9, no. 5, pp. 1844-1853, Oct. 2020, doi: 10.11591/eei.v9i5.2143.

[13] A. S. Sarvarov, V. F. Mikhaylets, A. E. Vasilev, and K. V. Danilenko, "Analytical study of underactuated mechanisms of anthropomorphic robotic gripper," in 2017 International Conference on Industrial Engineering, Applications and Manufacturing (ICIEAM), May 2017, pp. 1-5, doi: 10.1109/ICIEAM.2017.8076204.

[14] A. Ziv-Av, "Mechanical adjustable device," U.S. Patent No. 9,908,243, 2018.

[15] H. Heidari, M. J. Pouria, S. Sharifi, and M. Karami, "Design and fabrication of robotic gripper for grasping in minimizing contact force," Advances in Space Research, vol. 61, no. 5, pp. 1359-1370, Mar. 2018, doi: 10.1016/j.asr.2017.12.024.

[16] I. Llop-Harillo, A. Pérez-González, J. Starke, and T. Asfour, "The Anthropomorphic Hand Assessment Protocol (AHAP)," Robotics and Autonomous Systems, vol. 121, p. 103259, Nov. 2019, doi: 10.1016/j.robot.2019.103259.

[17] K. Xu, Z. Liu, B. Zhao, H. Liu, and X. Zhu, "Composed continuum mechanism for compliant mechanical postural synergy: An anthropomorphic hand design example," Mechanism and Machine Theory, vol. 132, pp. 108-122, Feb. 2019, doi: 10.1016/j.mechmachtheory.2018.08.015.

[18] M. A. Muslim, M. Rusli, A. R. Zufaryansyah, and B. S. K. K. Ibrahim, "Development of a quadruped mobile robot and its movement system using geometric-based inverse kinematics," Bulletin of Electrical Engineering and Informatics, vol. 8, no. 4, December 2019, doi: 10.11591/eei.v8i4.1623.

[19] A. A. Jaber and R. Bicker, "Development of a Condition Monitoring Algorithm for Industrial Robots based on Artificial Intelligence and Signal Processing Techniques," International Journal of Electrical and Computer Engineering (IJECE), vol. 8, no. 2, p. 996, Apr. 2018, doi: 10.11591/ijece.v8i2.pp996-1009.

[20] J. Zhang, R. Liu, K. Yin, Z. Wang, M. Gui, and S. Chen, "Intelligent Collaborative Localization Among Air-Ground Robots for Industrial Environment Perception,” IEEE Transactions on Industrial Electronics, vol. 66, no. 12, pp. 9673-9681, Dec. 2019, doi: 10.1109/TIE.2018.2880727.

[21] I. Parkhomey, J. Boiko, and O. Eromenko, "Identification information sensors of robot systems," Indonesian Journal of Electrical Engineering and Computer Science, vol. 14, no. 3, p. 1235, Jun. 2019, doi: 10.11591/ijeecs.v14.i3.pp1235-1243.

[22] J. Huang et al., "A strategy for human-robot collaboration in taking products apart for remanufacture," FME Transactions, vol. 47, no. 4, pp. 731-738, 2019, doi: 10.5937/fmet1904731H.

[23] A. Gupta, A. Singh, V. Verma, A. K. Mondal, and M. K. Gupta, "Developments and clinical evaluations of robotic exoskeleton technology for human upper-limb rehabilitation," Advanced Robotics, vol. 34, no. 15, pp. 1023-1040, Aug. 2020, doi: 10.1080/01691864.2020.1749926.

[24] M. Polishchuk and M. Tkach, "Mobile robot with an anthropomorphic walking device: Design and simulation," FME Transactions, vol. 48, no. 2, pp. 13-20, 2020, doi: 10.5937/fmet2001013P.

[25] V. Verma, P. Chauhan, and M. Gupta, "Distributed association rule mining with minimum communication overhead," Journal Européen des Systèmes Automatisés, vol. 52, no. 4, pp. 355-362, Oct. 2019, doi: 10.18280/jesa.520404.

[26] A. Kanada, F. Giardina, T. Howison, T. Mashimo, and F. Iida, "Reachability Improvement of a Climbing Robot Based on Large Deformations Induced by Tri-Tube Soft Actuators," Soft Robotics, vol. 6, no. 4, pp. 483-494, Aug. 2019, doi: 10.1089 /soro.2018.0115.

[27] I. Parkhomey, J. Boiko, N. Tsopa, I. Zeniv, and O. Eromenko, "Assessment of quality indicators of the automatic control system influence of accident interference," TELKOMNIKA (Telecommunication Computing Electronics and Control), vol. 18, no. 4, p. 2070, Aug. 2020, doi: 10.12928/telkomnika.v18i4.15601.

[28] M. Polishchuk, M. Suyazov, and M. Opashnyansky, "Study on numerical analysis of dynamic parameters of mobile walking robot," Journal of Mechanical Engineering and Sciences, vol. 14, no. 1, pp. 6380-6392, Mar. 2020, doi: 10.15282/jmes.14.1.2020.14.0499.

[29] D. Mukherjee, K. Gupta, L. H. Chang, and H. Najjaran, "A Survey of Robot Learning Strategies for Human-Robot Collaboration in Industrial Settings," Robotics and Computer-Integrated Manufacturing, vol. 73, p. 102231, Feb. 2022, doi: 10.1016/j.rcim.2021.102231.

[30] I. I. Plyaskin, "Optimization of technical solutions in mechanical engineering," Mechanical engineering, p. $176,1982$.

[31] I. Maurovic, M. Seder, K. Lenac, and I. Petrovic, "Path Planning for Active SLAM Based on the D* Algorithm With Negative Edge Weights," IEEE Transactions on Systems, Man, and Cybernetics: Systems, vol. 48, no. 8, pp. 1321-1331, Aug. 2018, doi: 10.1109/TSMC.2017.2668603.

[32] S. Gazut, J.-M. Martinez, G. Dreyfus, and Y. Oussar, "Towards the Optimal Design of Numerical Experiments," IEEE Transactions on Neural Networks, vol. 19, no. 5, pp. 874-882, May 2008, doi: 10.1109/TNN.2007.915111.

[33] J. Tang, G. Leu, and H. A. Abbass, "Experimental Design," in Simulation and Computational Red Teaming for Problem Solving, Wiley, 2019, pp. 101-120.

[34] I. Kovtun, J. Boiko, and S. Petrashchuk, "Nondestructive strength diagnostics of solder joints on printed circuit boards," in 2017 International Conference on Information and Telecommunication Technologies and Radio Electronics (UkrMiCo), Sep. 2017, pp. 1-4, doi: 10.1109/UkrMiCo.2017.8095401.

[35] V. Yaglinsky, A. Al-Obaydi, G. Kozeratsky, and N. Moskvichev, "Kinematics Rods of Simulator-Hexapod," British Journal of Applied Science \& Technology, vol. 16, no. 3, pp. 1-7, Jan. 2016, doi: 10.9734/BJAST/2016/26274.

[36] M. Polishchuk, M. Tkach, I. Parkhomey, J. Boiko, Y. Batrak, and O. Eromenko, "Intelligent machine for sorting semi-precious minerals," Indonesian Journal of Electrical Engineering and Computer Science, vol. 22, no. 3, p. 1354, Jun. 2021, doi: 10.11591/ijeecs.v22.i3.pp1354-1364. 


\section{BIOGRAPHIES OF AUTHORS}
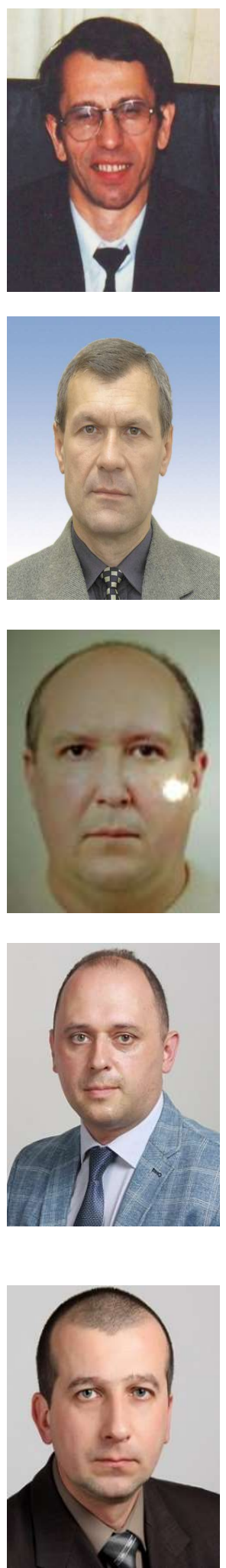

Mikhail Polishchuk (D) Bd SC $\mathrm{P}$ received his Specialist Degree and qualification as a mechanical engineer from the Kyiv Polytechnic Institute (Ukraine) in 1980. In 1986 he received a Candidate of Science $(\mathrm{PhD})$ degree from the Institute of Electric Welding named after Paton of the National Academy of Sciences of Ukraine in the field of automation of technological processes and assembly operations. Currently, he is an Associate Professor of the Department of Information Systems and Technologies at the National Technical University of Ukraine "Igor Sikorsky Kyiv Polytechnic Institute" (Kyiv, Ukraine). Research includes robotic systems in the field of modeling and design of industrial robots and automation of industrial processes. He can be contacted at email: borchiv@ukr.net.

Mikhail Tkach (D) SC SC received his Specialist Degree and Mechanical Engineer qualification from the Kyiv Polytechnic Institute (Ukraine) in 1981. In 1987 he received a PhD degree from the Kiev Polytechnic Institute (Ukraine) in the field of technological process automation. Currently, he is an Associate Professor of the Department of Information Systems and Technologies at the National Technical University of Ukraine "Igor Sikorsky Kyiv Polytechnic Institute" (Kyiv, Ukraine). Research includes information support for robotic systems in the development of tactile adaptation tools and design of robotic production facilities. He can be contacted at email: mm.tkach77@gmail.com.

Igor Parkhomey (D) PI SC P received his Specialist Degree and Radio Engineer qualification from the Kyiv Polytechnic Institute (Ukraine) in 1994. In 1999 he received a Ph.D. degree in technical sciences from the Kiev Polytechnic Institute in the field of system adaptive control design. In 2015, he received his Ph.D. in technical sciences from the State University of Telecommunications (Kyiv, Ukraine) in the development of radar systems. Currently, Professor of the Department of Information Systems and Technologies of the National Technical University of Ukraine "Igor Sikorsky Kyiv Polytechnic Institute" (Kyiv). Research includes issues related to the development of robotic devices. He can be contacted at email: i_parhomey@ukr.net.

Juliy Boiko (D) 8I SC $\mathrm{P}$ received a Specialist Degree and a Radio Design Engineer qualification from the Technological University of "Podillya" (Ukraine) in 1998. In 2002 he received a Candidate of Science degree $(\mathrm{PhD})$ at the Institute of Electrodynamics of the National Academy of Sciences of Ukraine in the field of device design and development of methods for measuring electrical and magnetic quantities. In 2015, he received a Doctor of Science degree (D.Sc. in Engineering) at the State University of Telecommunications (Kyiv, Ukraine) in the field of signal reception, synchronization, signal processing in telecommunication systems. Currently, Full Professor of the Department of Telecommunications, Media and Intelligent Technologies, Khmelnytskyi National University (Khmelnytskyi, Ukraine). Research includes issues related to the development of devices for the automation of devices and systems, the theory of automatic control, diagnostics, measurement and signal processing. He can be contacted at email: boiko_julius@ukr.net.

Oleksander Eromenko (D) 8 SC $\mathrm{P}$ received a Specialist Degree and a qualification of a teacher of physics and basics of computer science at the Kamyanets-Podilskyi State Pedagogical Institute (Ukraine) in 1997. In 2015 he received a Candidate of Science degree $(\mathrm{PhD})$ at the Khmelnytskyi National University in the field of radio-engineering devices and means of telecommunications. Currently, Associate Professor of Physics and Electrical Engineering Department, Khmelnytskyi National University (Khmelnytskyi, Ukraine). Research includes issues related to the development of devices for measurement and signal processing. He can be contacted at email: yeromenko_s@ukr.net. 